Sustainable Forestry (2019) Volume 2

doi:10.24294/sf.v1i3.932

\title{
Phytoremediation of Special Metals in Emerging Industries
}

\section{T. Y. Yeh" ${ }^{*}$, Min-Hao Wu' ${ }^{1}$ K F Chen ${ }^{2}$, Y P Peng ${ }^{3}$}

${ }^{1}$ Department of Civil and Environmental Engineering, National University of Kaohsiung, Taiwan, Tel: 886-7-591-9536, Fax: 886-7-591-9376, E-mail: tyyeh@nuk.edu.tw

${ }^{2}$ Department of civil engineering, National Chi Nan University

${ }^{3}$ Department of environmental engineering. Tunghai University

\begin{abstract}
This project is carried out to assess the remediation effect on soil contaminated by molybdenum (Mo), one of heavy metals, through the use of an energy crop, sunflowers. This project explores the integration of phytohormones and chelates in the phytoremediation of soils contaminated by heavy metals, and further assesses the operational measures of remedying heavy-metal contaminated soil with sunflowers, in addition to the related environmental factors. Then the project explores phytohormones and heavy metals on the growth scenario explants (explants morphological analysis) through the experiment. The results indicate that $\mathrm{GA}_{3}$ can increase the growth rate of the plants. The average incremental growth of the heavy-metal-added-only group is $21.0 \mathrm{~cm}$; of the $\mathrm{GA}_{3}$-added group it is $21.9 \mathrm{~cm}$; of the EDDS-added group, it is $20.3 \mathrm{~cm}$; of the $\mathrm{GA}_{3}+$ EDDS-added group, it is $21.7 \mathrm{~cm}$. Compared with the conventional methods of phytoremediation, these integrated measures can actually spur the growth of plants.
\end{abstract}

Keyword: Mo; GA3; EDDS; Phytoremediation

\section{Introduction}

In recent years, the development of the opto-electronic industry has exerted a vast impact on the environment. For instance, certain enterprises discharge wastewater into rivers or irrigation channels without treatment; thus, the farmlands have been contaminated by heavy metals through irrigation. In China, the area of such contamination is very large, and the concentration of the pollutants is very high, thereby creating a difficult challenge to remove these pollutants. On the other hand, while the polluted area and pollutant concentration in Taiwan are relatively lower than their counterparts in China, the 2013 Annual Report of Remediation presents statistics whose significance cannot be underestimated. According to the Report, the current declared control sites in Taiwan cover 420.8 hectares in total; 234.3 hectares of them are farmlands, accounting about 55.68\%. Although it is rare to see farmland contamination caused by heavy metals discharged from emerging industries, certain plants may be poisoned due to the various crops' uptake of heavy metals. In addition, when there is too much heavy metal accumulation in the soil, the crops will absorb the heavy metals from the soil and subsequently negatively impact human health through the food chain. Moreover, unlike organic matter, heavy metals are non-biodegradable, which means that they cannot be degraded by the microorganisms in the soil, and therefore will accumulate in the environment. Once heavy metals enter human body through the food chain, they will also accumulate there since metabolism cannot degrade them. The purpose of this project is thus to understand the heavy metal transport process in soil, through research on the molybdenum (Mo) elimination via phytoremediation.

Compared with conventional physicochemical remediation, ecological phytoremediation is relatively economical, and can achieve sustainable resource use more easily since it belongs to "Green Technology". In addition, phytoremediation can remedy the soil composed of physiochemical compounds and contaminated by both organic and inorganic pollutants; thus, the structure and texture of the soil will not be destroyed, and the soil fertility will be unaffected. Moreover, this procedure can be more acceptable for people living in the remediation areas since it is environmentally- friendly as it greens the landscape. The process of phytoremediation includes phytoextraction,

Copyright (C) 2019 T. Y. Yeh et al.

doi: 10.24294/sf.v1i3.932

EnPress Publisher LLC.This work is licensed under the Creative Commons Attribution-NonCommercial 4.0 International License (CC BY-NC 4.0).

http://creativecommons.org/licenses/ by/4.0/ 
phytostabilization and rhizofiltration. To increase the efficacy of phytoremediation for heavy metal elimination in an efficient way, it is suggested to adopt hyperaccumulator plants, which have higher tolerance to heavy metals, better uptake efficiency, and which can grow faster and rapidly increase their biomass. Besides, it is also suggested that chemical chelate can be applied to enhance the phytoextraction.

Due to global warming, the greenhouse effect and the global energy crisis, scientists from different fields are working on the research and development of alternative energies. Alternative energies are replacements of fossil fuels, and they will not emit carbon dioxide. They are divided into two major categories: nuclear energy and renewable energy. Bioenergy is a form of renewable energy, including: refuse derived fuel (RDF), bio-diesel, bio-ethanol, and waste-activated sludge. In Taiwan, more than $90 \%$ of the required energy must be imported from other countries; since the country lacks natural energy resources, it is necessary for Taiwan to develop new technologies to produce bioenergy. As the oil sources become depleted, there will be more conflicts over energy around the world, causing increased oil prices. For Taiwan, developing bioenergy can not only raise its energy independence, but also activate large areas of fallow farmlands, bringing more jobs to rural areas, and creating a new energy industry for the nation's economic development. Moreover, when plants which can both produce bioenergy and absorb high level accumulation heavy metals are found, they can be applied to create double effects on controlling heavy metal pollutants and providing bioenergy. Lin Chieh-Yih (2007) indicates that the high oil content crops in Taiwan which can produce biodiesel include soybeans, sunflowers and rape plants. Consequently, sunflowers are adopted for the phytoremediation in this research, with the integration of phytohormones and chelates to enhance the phytoremediation effects of heavy metal contamination.

\section{A. Phytoremediation}

Since heavy metals are non-biodegradable, they can easily accumulate in the environment, enter the human body and negatively affect human health through the food chain; thus, the remediation of heavy metal contamination is particularly important. Conventional physicochemical remediation is costly and requires more human labor. Besides, it destroys the soil structure, texture and fertility because it requires excavation. On the other hand, phytoremediation is an environmentally- friendly Green Remediation which can achieve sustainable development. It reduces the pollutants and toxicity contained in soil with the use of plants as well as the microorganisms in the soil. As it can green the landscape and improve the scenery of the environment, the process will be more acceptable to people compared to conventional remediation.

\section{Applicable Pollutant}

Phytoremediation can remove not only heavy metals but also organic or inorganic pollutants from the sediments or soils containing complex substances.

\section{Treatment Objects and Operation Methods}

In phytoremediation, the plants are the only ones that need further treatment; thus, the original characteristics, structures and the ecologies of the soils will not be destroyed.

\section{Reduce Secondary Contaminations}

Phytoremediation can remedy pollutants in situ to avoid the dangers of pollutant exposure derived from its transport; therefore, it is more acceptable to people.

\section{Green New Concept}

Phytoremediation is a green remediation technology which can improve sceneries and achieve sustainable use.

\section{The Innovation of Phytoremediation Techniques}

The process of phytoremediation includes phytoextraction, phytostabilization and rhizofiltration, which are further described respectively as follows:

(1) Phytoextraction: the root of the plants will absorb organic matter and heavy metals from the soil, and accumulate these substances in different parts through xylem transport. After a period of time for the uptake, the plants will be removed for further treatment, usually by incineration or filling. During the remediation period, the growth rates 
and harvesting times of the plants will be assessed to prevent the plants from dying, because the heavy metals would thus be re-released into the environment.

(2) Phytostabilization: through the function of their roots, the plants absorb the organic matters and heavy metals from the soil, then condense the heavy metals and attach them to root parts, thereby reducing the bioavailability and transport of the pollutants, so that the pollutants can be degraded in the environment or evaporate in the air. The plants adopted for this method are low accumulative; thus the possibility of the plants becoming hazardous wastes is reduced.

(3) Rhizofiltration: this is the method for absorbing and condensing heavy metals in medium via plant roots. Poaceae are the plants exhibiting the most significant effects of rhizofiltration because their roots grow faster and cover larger surface areas.

To assess the efficacy of phytoremediation to remove heavy metals, the bioconcentration factor (BCF), translocation factor (TF) and phytoremediation efficiency factor (PEF) are all commonly adopted in the assessment.

$$
\begin{gathered}
B C F=\frac{C_{\text {root }}}{C_{\text {soil }}} \\
T F=\frac{C_{\text {shoot }}}{C_{\text {root }}} \\
P E F=\frac{C_{\text {shoot }}}{C_{\text {soil }}}
\end{gathered}
$$

In the above formula, $\mathrm{C}_{\text {soil }}, \mathrm{C}_{\text {root }}$ and $\mathrm{C}_{\text {shoot }}$ represent the concentration of the soil, underground part of plants (i.e. the roots) and above parts of plants (i.e. the shoots and leaves), respectively.

The BCF offers a comparison between heavy metal accumulations in plant roots and in soil. Higher BCF value suggests better efficacy of a plant's heavy metal uptake from the soil. Phytoremediation requires harvesting plants in an appropriate manner to ensure that the heavy metal pollutants are well removed from the contaminated soil. If a plant has better transport, it can easily transport heavy metals to the shoots and leaves. The greater the heavy metal accumulation in the biomass of plant shoots and leaves, the more heavy metals that can be removed from the soil after harvesting. On the other hand, TF presents a comparison between heavy metals accumulations in plant shoots, leaves and roots to assess the plant's transport capacity of heavy metals from the roots to the shoots and leaves. Higher TF value signifies better transport efficacy of heavy metals from roots to shoots and leaves.

\section{B. Introduction to Transition Metals}

Transition metals are the major pollutants in agricultural ecology. They are non-biodegradable trace metals, and have a high affinity with anoxic sediments, fine clay, silt and detrital particles, causing sulfate reduction (Kabata-Pendias and Pendias, 1984; Alloway, 1990; Kabata-Pendias, 2001). In intensive farming, the transition metal contamination results from pesticides and compost due the fact that the process of soil decontamination is slow and regional, and because the pollutants can accumulate easily in soil (Kabata-Pendias, 2001) with various chemical forms that affect the metal's bioavailability. In addition, different soil characteristics can have a huge impact on the accumulation of transition metals, such as the content of organic matter (Alloway, 1990). Transition metals can also affect ammonia metabolism, especially its usability and uptake (Rai et al., 1993; Siedlecka, 1995).

Mo is one of the essential trace metals required for plant growth. However, when the volume of Mo in soil is excessive, it will poison the plants and make the leaves become yellow or brown after uptake; the growth of plant roots and tillers will be affected. The effectiveness of Mo in soil is affected by the soil's $\mathrm{pH}$ value. Mo will become ineffective in strongly acidic soil; thereby, it will be unable to be absorbed by plants. Mo can be absorbed by plant roots in the form of ions, or directly from the leaves. Different plants have different levels of Mo uptake, but the content in leaves is usually larger than in other plant parts. 


\section{Correlation between Binding Fraction of Heavy Metals in Soil and Phytoremediation}

In phytoremediation, the process of extracting heavy metals from the soil is related to the content of organic matter in the soil. Organic matter usually undergoes complexation with heavy metals, affecting plants' uptake efficiency; the cation exchange capacity (CEC) and the content of organic matters in soil affect the bioavailability of heavy metals in the medium. The binding of heavy metals to soil particles signifies the bioavailability of heavy metals in the soil medium, and it can affect the efficacy of phytoremediation. The chemical sequential extraction procedure is the measure used to understand the binding fraction of heavy metals in soil. Generally, the method proposed by Tessier et al. (1979) is the one commonly adopted. It divides the binding of heavy metals to soil particles into five forms: adsorption and exchangeable fractions, carbonate-bound, $\mathrm{Fe} / \mathrm{Mn}$ oxide-bound, organic matter bound and residual fractions. In the binding of heavy metals with soil particles, the adsorption and exchangeable fractions can be applied in assessing the impact of heavy metals on the environment; $\mathrm{Fe} / \mathrm{Mn}$ oxide-bound and organic matter bound are the major binding fractions of heavy metals possessing potential mobility in soil; residual fractions are the most stable binding fractions that have the least feasibility of being re-released from the binding fractions of heavy metals back into the soil. The background characteristics of soil, including the concentration of electron donors, soil adsorption, $\mathrm{pH}$ values and organic matter can affect not only its adsorption of heavy metals, but also the potentiality of heavy metals being released into the environment.

\section{Biodegradable Chelates}

Conventional phytoremediation removes pollutants from soil by planting hyperaccumulators. However, there are various pollutant sources of the heavy metals in soil, and since hyperaccumulators usually have the best performance only when absorbing a single type of heavy metal in soil, they have limited phytoremediation efficacy when dealing with more than two types of heavy metals in soil. To increase the efficiency of phytoremediation, recent research presents that adding chelates can increase the mobility of heavy metals in soil, as well as the efficacy of plants' adsorption and transport of heavy metals. Nowack et al. (2006) indicate that chelates can increase the efficiency of phytoremediation via two major mechanisms: enhancing the mobility and transport of heavy metals in soil, and assisting plants in absorbing and transmitting the metal-chelate complex. Adding chelates can improve the efficiency of plants' extraction activity, and enhance the efficiency of plants' heavy metal uptake, as well as the transport from plants' root and shoot parts. Chelates' dissolution and complexation of heavy metals can increase both heavy metals' mobility and transport from plant roots to the above parts of plants, and the heavy metal complex can accumulate in the roots and then be effectively transmitted to the above parts of plants. Chelates can be divided into non-biodegradable chelates and biodegradable chelates. EDTA (ethylenediaminetetraacetic acid, C10H16N2O8), one of the non-biodegradable chelates, has been commonly applied to increase the efficiency of phytoremediation. It is commonly applied in soil remediation because of its strong complexation capability. Although it can effectively increase the mobility of heavy metals, its non-biodegradable properties may lead to underground water contamination. Adding chelates can affect the heavy metals in soil, and is one of the critical factors related to the efficiency of phytoremediation. When conducting phytoremediation, adding biodegradable chelates or organic acids can modify the binding of heavy metals to soil particles, improve the efficacy of phytoremediation and prevent underground water from derivative issues such as second contamination. The EDDS (ethylenediaminedisuccinic acid, C10H13N2O8), one of the biodegradable chelates, has attracted much attention in recent years because it can be easily degraded by soil, and therefore produce fewer hazardous by-product materials. Its complexation with heavy metals such as $\mathrm{Cr}, \mathrm{Fe}, \mathrm{Pb}, \mathrm{Cd}, \mathrm{Na}, \mathrm{Cu}$ and $\mathrm{Ni}$ can also be biodegraded, except for the Hg-EDDS complex since it is poisonous. Meers et al. (2007) conducted an experiment with five willows to examine the feasibility of phytoremediation of soils contaminated respectively by $\mathrm{Cd}$, $\mathrm{Cr}, \mathrm{Cu}, \mathrm{Ni}, \mathrm{Pb}$ and $\mathrm{Zn}$. The researchers added EDDS to three different contamination levels of soils in conducting the experimental phytoremediation. The results indicated that the plants had better performances in the uptake of $\mathrm{Cd}$ and $\mathrm{Zn}$. In the soils with high heavy metal concentration levels, adding EDDS can increase Cd contents in plant shoots by $60 \%$, and in leaves by $35 \%$, compared to the control group; whereas in the soil collected from an abandoned mine, the 
increment of absorbed contents in shoot and leaves was $97 \%$ and $45 \%$, respectively. However, the addition of EDDS did not increase the plants' mass, which might be due to the biohazards caused by the over-uptake of heavy metals. Evangelou et al. (2007) conducted another experiment to assess the efficacy of tobacco's uptake of heavy metals; the results indicated that adding too much EDDS can be poisonous to tobacco. In the experiment, the researchers added EDDS to the plants with concentrations between 1.5 and $50 \mathrm{mmol} / \mathrm{kg}$; the poisonous effects of the tobacco occurred when the concentration level reached 3.125 mmol. Moreover, the group with lower concentration levels in the experiment showed that adding EDDS can be effective in absorbing $\mathrm{Cu}$, which was mostly accumulated in the plant roots. The separate addition of EDDS and EDTA (with the concentration level of $1.5 \mathrm{mmol} / \mathrm{kg}$ ) increased the efficacy of $\mathrm{Cu}$ uptake by $700 \%$ and by $1200 \%$, respectively, but failed to significantly increase the efficacy of Cd uptake. These results indicate that adding chelates to the soil contaminated by multiple heavy metals cannot enhance plants' capability of absorbing heavy metals. The addition of EDDS and EDTA improves the efficacy of $\mathrm{Cu}$ uptake, but with no significant increment of Cd uptake. EDDS is a chelate which can be easily biodegraded, and certain researchers pointed out that its half-life in soil is 2.5 days, meaning that the contents of EDDS in soil will be reduced rapidly as time passes (Luo et al., 2005). EDTA and EDDS mixed together perform better than when used individually. It can enhance the efficacy of phytoremediation, and reduce the possibility of extracted heavy metals penetrating to deeper soil or underground water, thereby preventing the soil from secondary contamination and enlargement of contamination area. Luo et al. (2005) conducted an experiment to assess the influence of adding EDDS or EDTA for the $\mathrm{Pb}$ and $\mathrm{Cd}$ uptake of wheat and beans; the results indicated that EDDS performed worse than EDTA because of its biodegradability, after having a complexation reaction with heavy metals. The impact of heavy metals on EDDS's biodegradability is arranged as follows from bigger to smaller: $\mathrm{Cd}>\mathrm{Pb}>\mathrm{Zn}>\mathrm{Cu}$. In other words, the Cd-EDDS complex and Pb-EDDS complex will be biodegraded before being absorbed by plants. The effect of chelate on extracting heavy metals in soil can serve as a reference for assessing the efficiency of plants' heavy metal uptake. The results of the experiment presented that the comparison of EDDS, EDTA and water regarding the performance of $\mathrm{Cu}$ and $\mathrm{Zn}$ extraction is arranged in order as: EDDS > EDTA > water; and for the $\mathrm{Pb}$ and $\mathrm{Cd}$ extraction, the performance comparison is arranged as: EDTA > EDDS $>$ water. These results correspond with the results of plants' heavy metal accumulation after adding chelates into the soil.

\section{E. Application of Phytohormones}

Phytohormones increase plant growth and biomass (Tassi et al., 2008), so they should perform well in enhancing the effect of phytoremediation of heavy metal polluted soil. Generally, phytohormones can be divided into various categories: auxins (including Indole-3-acetic acid, IAA; and Indole-3-butyricacid, IBA), gibberellins (according to relevant documents, there are over 70 types of gibberellins, and Gibberellic acid; $\mathrm{GA}_{3}$ is the most common one), and cytokinins (CK). Liphadzi et al. (2006) planted sunflowers respectively in soils with high or medium levels of contamination. The results exhibited that adding IAA to soil with medium levels of contamination can effectively increase the biomass of plant roots, but not for soil with high levels of contamination. The experiment further indicated that IAA can reduce the impact of heavy metals on plants. The relevant character information regarding the commonly used phytohormones (IAA, $\mathrm{GA}_{3}$ and CK) is listed in Table 1. López et al. (2005) conducted a hydroponic experiment to examine the effect of IAA and EDTA on the Pb uptake of Medicago Sativa; the results showed that the combination of $100 \mu \mathrm{M}$ IAA/0.2 mM EDTA increased the $\mathrm{Pb}$ accumulation in leaves by about $2800 \%$ and by about $600 \%$, respectively. Liu et al. (2007) also conducted an experiment to evaluate the effect of IAA combined with EDTA to enhance the $\mathrm{Pb}$ uptake ability of Sedum alfrediiHance; the result indicated that IAA and EDTA produced a synergistic effect by dramatically increasing $\mathrm{Pb}$ transport in plant shoots. In addition, Israr et al. (2008) also indicated that $100 \mu \mathrm{M}$ IAA can increase the $\mathrm{Pb}$ accumulation in the above parts of Sesbania drummondii by $600 \%$ compared to the control group, and the $\mathrm{Pb}$ accumulation can further increase the level to $1000 \%$ when combined with EDTA. Fässler et al. (2010) conducted an experiment by combining IAA with EDDS to examine the efficacy of alleviating toxic effects of $\mathrm{Pb}$ and $\mathrm{Zn}$ on sunflowers; the results indicated that IAA can alleviate the toxic effects of $\mathrm{Pb}$ and $\mathrm{Zn}$ on plants (such as the shoot 
and root dry weight, root length, root volume and root surface area); in combination with EDDS, it can increase the phytoextraction potential of these plants. Another experiment conducted by Hadi et al. (2010) presented that applying $\mathrm{GA}_{3}$ and IAA onto the leaves of Zeamays L. with foliar spray significantly increased the $\mathrm{Pb}$ accumulation in plants. Furthermore, combining $\mathrm{GA}_{3}$ with IAA or EDTA can effectively increase heavy metal accumulation in plants; GA 3 performs better than IAA in increasing the plants' $\mathrm{Pb}$ transport. Certain researchers in the previous studies integrated $\mathrm{CK}$ with EDTA to facilitate the phytoremediation effect on abandoned industrial sites contaminated by $\mathrm{Pb}$ and $\mathrm{Zn}$, by using sunflowers (Helianthus annuus). The results showed that combining EDTA with CK can effectively facilitate the plants' uptake efficiency of $\mathrm{Pb}$ and $\mathrm{Zn}$. The results also indicated that $\mathrm{CK}$ can assist phytoremediation in increasing plants' biomass, accumulation of metals in the above parts, as well as the transpiration of plants (Tassi et al., 2008).

\begin{tabular}{|c|c|}
\hline 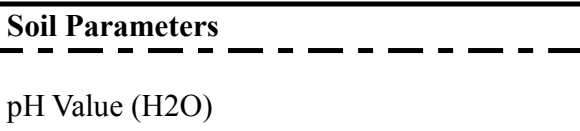 & 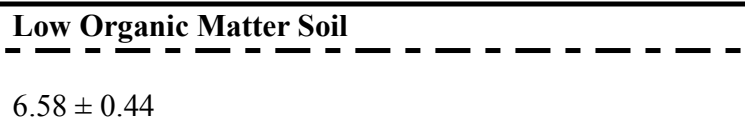 \\
\hline Organic Matter(\%) & $4.16 \pm 0.27 \%$ \\
\hline Clay $(\%)<2 \mu \mathrm{m}$ & $15.19 \%$ \\
\hline Silt (\%) $2-50 \mu \mathrm{m}$ & $78.69 \%$ \\
\hline Sand (\%) $50-2000 \mu \mathrm{m}$ & $6.12 \%$ \\
\hline $\mathrm{Cu}$ background concentration in soil (mg/kg) & $31.26 \pm 4.72$ \\
\hline Zn background concentration in soil $(\mathrm{mg} / \mathrm{kg})$ & $185.55 \pm 6.34$ \\
\hline $\mathrm{Pb}$ background concentration in soil (mg/kg) & $0 \pm 0.01$ \\
\hline
\end{tabular}

\section{F. Energy Crops}

Table 1. Soil Background Parameters

Currently, the most common sources for biodiesel production are the oil seeds, including: soybeans, cottonseeds, castor beans, safflower seeds, sunflower seeds, rapeseeds, coconuts and oil palm seeds. Excluding cottonseeds and castor beans, most of them are seeds of edible crops, which will affect food supply when they are applied in the biodiesel production since they are under-yielding and costly. For instance, the growing period of soybeans is short (90 - 120 days), the yield is 2.5 - 3.5 tons per hectare, and the oil content is only $20 \%$. The growing period of sunflowers is short as well (120 days), and the yield is only $1-2$ tons per hectare, although the oil content can reach $35 \%$. The production of both soybeans and sunflowers is affected greatly by the weather. When typhoons and storms come, the crops may easily collapse, and the seeds will rot, so that nothing will be harvested. Even if the weather factor can be excluded, the yields of soybeans and sunflowers oils are still only between 500 and 700 liters. As for rape plants, the growing period is $120-160$ days, the yield is $2-2.5$ tons per hectare and the oil content can reach $40 \%$. The oil production per area of rapeseeds is slightly higher than that of soybeans and sunflower seeds.

An ideal energy crop will have the following characteristics: non-edible crops, suitable to be planted in barren lands (so that farmlands will not be affected), fast growth, short growing period, high productivity, perennial plants, easy to propagate, feasible for extensive farming or ratoon cropping, strong adaptability (tolerant to drought, cold and heat), disease and insect resistant, easy to manage (fertilizing, irrigating and grass cutting), machine harvestable, easy to carry, high quality (high active component) and high conversion efficiency. The abovementioned characteristics determine the production costs and economic benefits. In addition, the most common indicator for choosing energy crops is the energy out/input ratio; only when the ratio is larger than 1 can the economic benefits be effective. Considering food safety, it is suggested that the development of the second generation of bioenergy in Taiwan should be 
implemented without occupying farmlands, consuming foods or destroying the ecology. Firstly, it shall actively promote farmers to re-cultivate foods, feed crops or energy crops in fallow lands, so that more job opportunities can be created, the agroforestry economy can be activated and the use of autonomous energy can be increased.

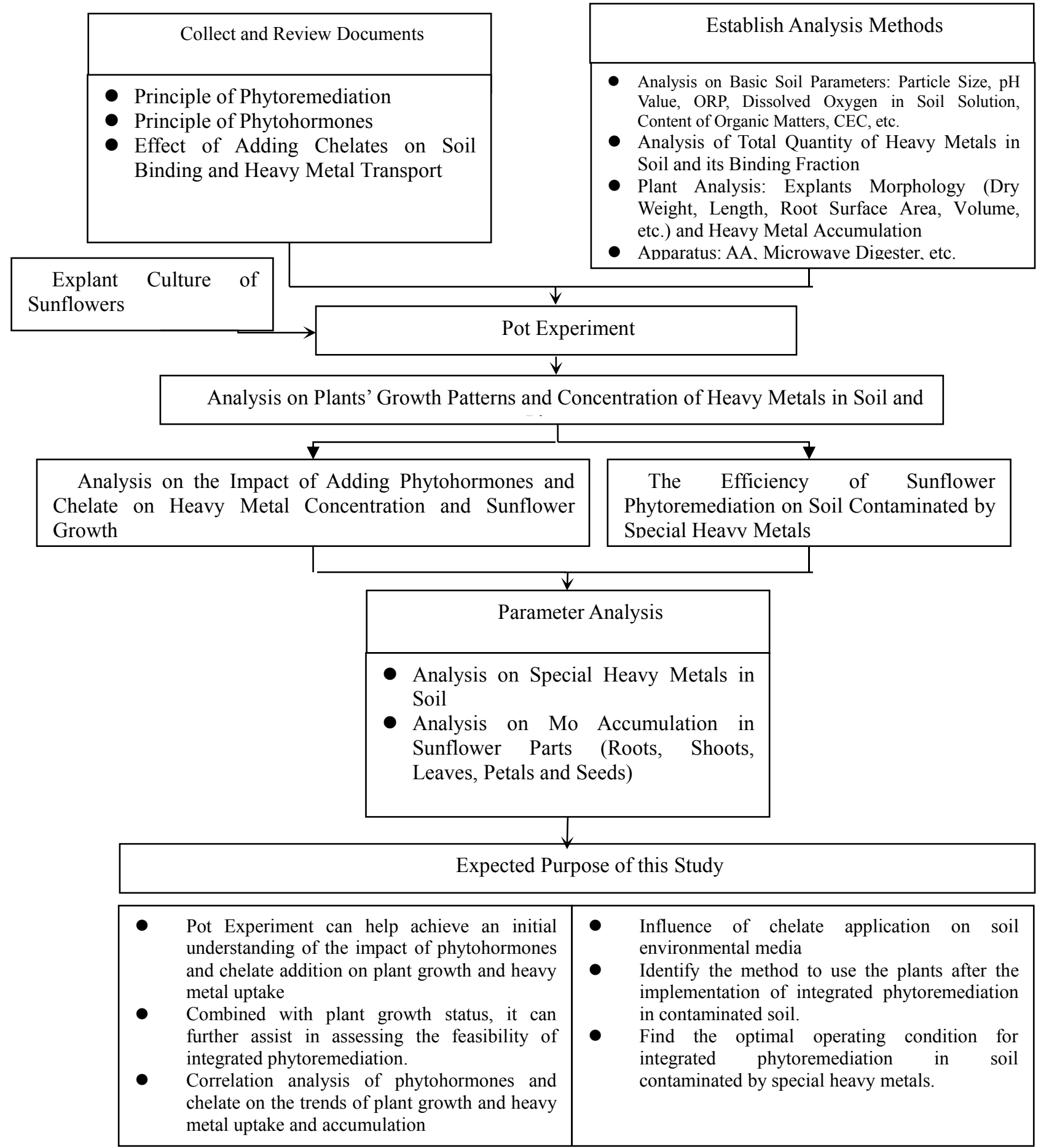

Figure 1; Process Table of the research.

Biodiesel is mainly produced from natural plant oils, animal fats, by-products of oil purification, used cooking oil or industrial waste oil. Biodiesel has many advantages. For instance, since it has similar burning characteristics to fossil fuel, it can be blended with diesel at any ratio, thus either fully replacing diesel for diesel vehicles without any modification of the engines required, or be mixed with gasoline for use. Secondly, it is safer to transport and store as its flash point $\left(118^{\circ} \mathrm{C}\right)$ is higher than that of fossil fuel $\left(52^{\circ} \mathrm{C}\right)$. In addition, biodiesel has higher oxygen content $(11 \%)$, 
making it easier to achieve complete combustion; thus, it emits less byproducts resulting from incomplete combustion such as carbon monoxide (CO). Compared with fossil fuel, B100 (100\% biodiesel) can reduce CO emission by $50 \%$, particulates by $70 \%$ and hydrocarbons by $40 \%$. Moreover, since biodiesel has virtually no sulfur content, there is no sulfur emission from biodiesel usage. As a result, using biodiesel can reduce poisonous substances in the gas emitted by burning fossil fuels, such as aromatic hydrocarbons and sulfides. It can also further assist in reducing the greenhouse effect caused by nitric oxides and hydrocarbons. Another advantage of biodiesel is its lubricating property. A small addition can reduce engine friction like a lubricant. Consequently, biodiesel is a renewable energy that is environmentally friendly, sustainable, easy to produce, biodegradable and produces low pollutant emissions.

\section{Materiel and methods}

In this chapter, the methodology of the study is introduced, including the relevant parameters of the pot experiment, background values of the soil, information about the phytohormones and the chelates, the method of analysis on heavy metal content in soil and plants, as well as the framework and assignment of the implementation.

\subsection{Implementation Measures}

\subsubsection{Pot Experiment}

The implementation of the pot experiment is demonstrated in Figure 2. First of all, the non-organic soil was purchased from a garden shop for the experiment; the background parameters are listed in Table 1. After being dried by heat, Mo was added to the soil, and then distributed into several pots; each pot was filled with $10 \mathrm{~kg}$, and the $\mathrm{pH}$ value remained neutral. On the basis that the plants would not die, the Mo was properly mixed with the soil, and the concentration complied with legal standards. After the addition of Mo was completed, the researcher dried the soil under the sun, added $500 \mu \mathrm{mol} / \mathrm{kg}$ chelates (EDDS), and stirred it properly before re-drying it under the sun. The relevant parameters are shown in the Table below. When the additions of the heavy metal and the chelate were completed, and the soil was fully heat dried, the researcher planted four sunflowers in each pot, and then divided the pots into four groups: water+Mo group, water $+\mathrm{Mo}+\mathrm{GA}_{3}$ group, water $+\mathrm{Mo}+\mathrm{EDDS}$ group and water $+\mathrm{Mo}+\mathrm{GA}_{3}+\mathrm{EDDS}$ group. The sunflowers were exposed to sunshine in a cycle of $16 \mathrm{~h} / 8 \mathrm{~h}$ (day/night). During the experiment, the phytohormones $\left(\mathrm{GA}_{3}\right)$ was sprayed once every morning and evening for a month. The relevant information on the phytohormones $\left(\mathrm{GA}_{3}\right)$ and the chelate (EDDS) is demonstrated in Tables 3 and 4. One month later, the plants' growths were compared first, and then the plant parts were collected and divided into two categories for further analysis: root part, and the above parts (shoots, leaves, petals and seeds). The analysis of the Mo concentration was then conducted to compare the volumes of accumulated Mo in different plant parts, and to identify the optimal quantity of the addition for sunflower plants. Finally, the researcher combined different conditions together to adjust the ratio of phytohormones/chelate addition in the hope that the maximum efficacy of phytoremediation could be achieved.

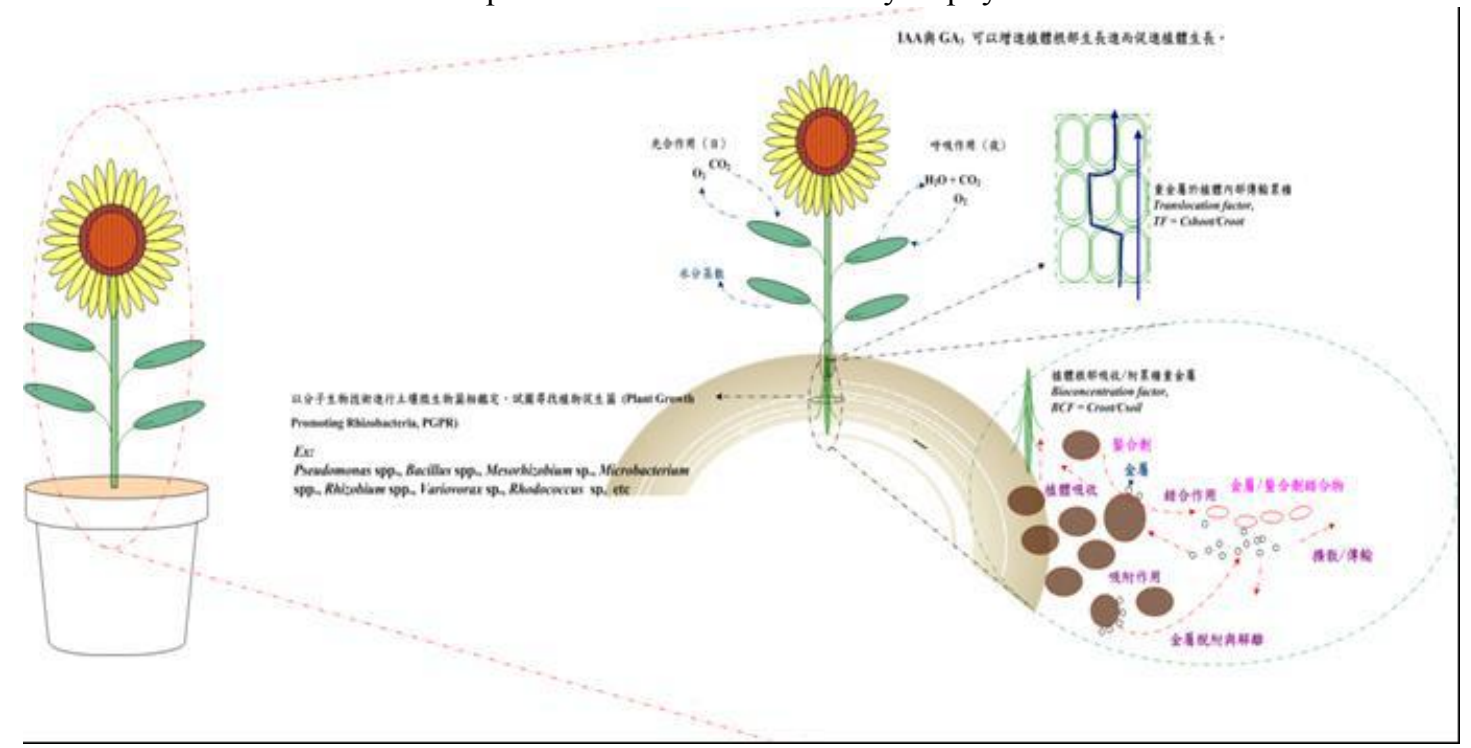

Figure 2; Implementation of Pot Experiment. 


\subsection{Calculation on Mo Concentration}

Based on mass balance, the researcher assumed that all the discharged waste water flowed into the farmlands and caused the contamination; thus, the applied Mo concentration was calculated as follows.

Total quantity of discharged wastewater in Taiwan times effluent control standards, divided by contaminated farmland areas in Taiwan yields the Mo concentration per unit area. After the calculation, the researcher concluded that the concentration was $0.01 \mathrm{mg} / \mathrm{cm}^{2}$. Since the area of each pot is $1200 \mathrm{~cm}^{2}, 12 \mathrm{mg}$ of Mo should be added into the pot soil.

Phytohormones can facilitate the growth of stems and leaves, and make petals grow and blossom earlier. They can also assist in facilitating the germination of seeds, root tubers and stem tubers, stimulating fruit growth, and increasing the fruit-set or the odds of forming seedless fruits.

\subsection{Analysis of Plant Growth Status}

The first day when the pot experiment was started, the plants' heights were measured and recorded. Afterwards, the recording of the plant growth was conducted regularly, every week for a month. After the experiment was finished, the plant height growth was compared with the addition of tolerance, and the biomass was measured to discuss whether the addition of $\mathrm{GA}_{3}$ and $\mathrm{EDDS}$ can increase the plants' biomass.

\subsection{Heavy Metal Analysis}

The soil in the pot experiment was digested by aqua regia for the extraction of Mo from the soil. First, the soil was dried in an oven at $104^{\circ} \mathrm{C}$, and screened by $\# 20$ mesh. After that, $0.5 \mathrm{~g}$ of soil was mixed with nitric acid and hydrochloric acid at the respective volumes of $3.0 \mathrm{ml}$ and $9.0 \mathrm{ml}$, microwave-digested by MarsX microwave digester and analyzed by using AA. The pot sunflowers were separated into parts; roots, shoots, leaves and petals, and then dried in the oven at $104^{\circ} \mathrm{C}$ for $24 \mathrm{~h}$ before being ground. After that, the $0.5 \mathrm{~g}$ plant parts had $5.5 \mathrm{ml}$ nitric acid and $0.5 \mathrm{ml}$ hydrochloric acid added, respectively, for extraction, and then microwave-digested by MarsX microwave digester before being analyzed with AA. The parameter setting of MarsX microwave digester is shown in Table 5 .

\section{Results and Discussion}

\subsection{Difference Results of Pot Experiment in Different Operation Conditions}

According to previous research, the optimal operation parameter for integrated phytoremediation is the addition of $\mathrm{GA}_{3}$ and EDDS at the respective concentrations of $10^{-8} \mathrm{~mol} / \mathrm{kg}$ and $500 \mathrm{umol} / \mathrm{kg}$, which can effectively increase the plant height growth, as well as the accumulated quantity of heavy metals transmitted from the roots to the above parts. Therefore, these operation parameters were adopted in this experiment for further assessment.

The pots in the experiment simulated Mo contamination, and were divided into four groups: Mo group, $\mathrm{Mo}+\mathrm{GA}_{3}$ group, Mo+EDDS group and Mo+ $\mathrm{GA}_{3}+\mathrm{EDDS}$ group. The plant growth in the four groups was observed on Days 1, 15 and 30, and the heavy metal accumulation and uptake in plants were assessed after the plants were harvested.

\subsection{Discussion on Sunflower Plant Growth in Different Operation Conditions}

The growth of the sunflowers was observed on Days 1, 15, and 30. Figure 4 is a boxplot presenting the plant heights of the sunflowers after 30 days. From Tables 7 to 10, the average height growth of the sunflowers in the four groups are shown as follows: $21.0 \mathrm{~cm}$ for Mo group, $21.9 \mathrm{~cm}$ for $\mathrm{Mo}+\mathrm{GA}_{3}$ group, $20.3 \mathrm{~cm}$ for Mo + EDDS group and $21.7 \mathrm{~cm}$ for $\mathrm{Mo}+\mathrm{GA}_{3}+$ EDDS group. 


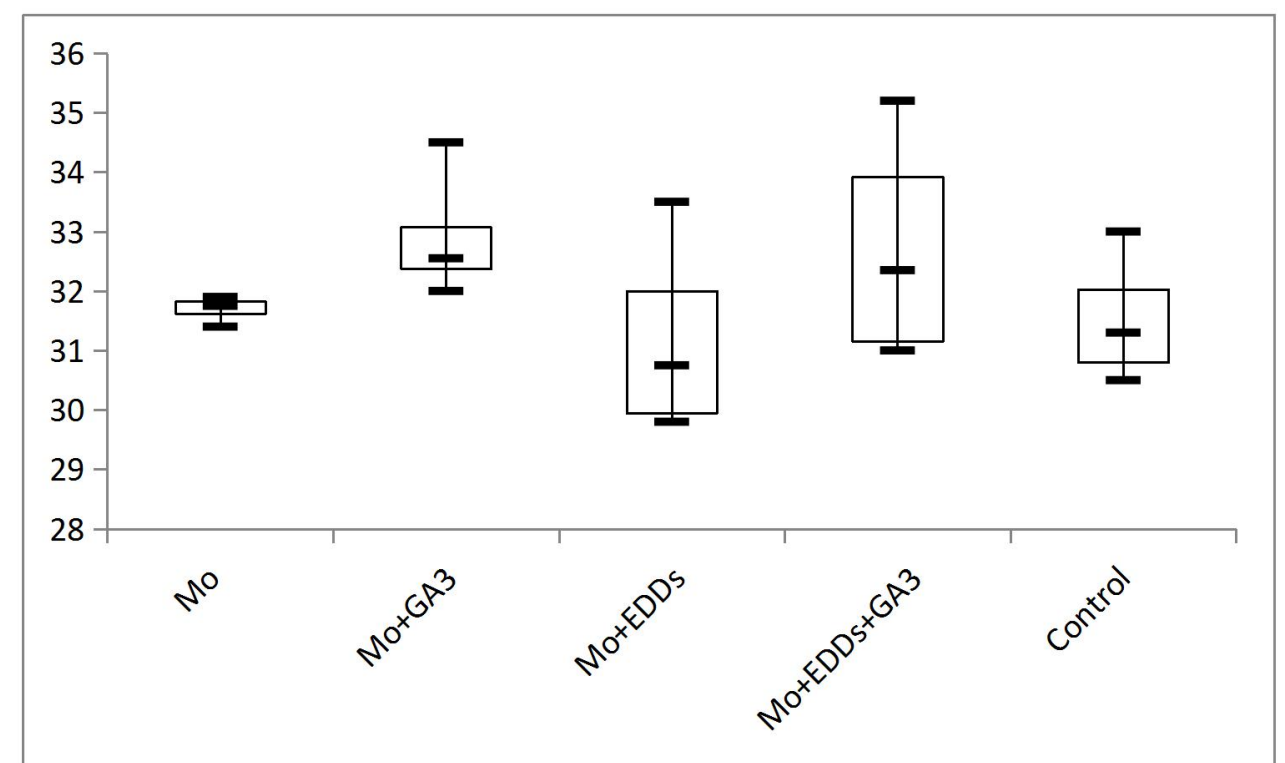

Figure 4; Boxplot of sunflowers' height growth for the respective groups on Day 30 of the pot experiment.

The results showed that the plants of $\mathrm{Mo}+\mathrm{GA}_{3}$ group and $\mathrm{Mo}+\mathrm{GA}_{3}+$ EDDS group had grown higher after 30 days, whereas Mo + EDDS group had grown comparatively less, proving that the addition of $\mathrm{GA}_{3}$ can enhance the effect of adding EDDS on sunflower growth. On the other hand, although the height growth of the sunflowers in Mo group was the least, the median was the same as for the Mo + EDDS group, and the individual height growth were more consistent, unlike the ones of Mo + EDDS group, which were irregular. In addition, according to the ANOVA test, the P value was larger than 0.05 , suggesting that there was no statistical difference among the four groups. Therefore, it is concluded that the influence of adding EDDS on the height growth of sunflowers is not significant.

\begin{tabular}{lllll}
\hline Groups & $\begin{array}{l}\text { Individual } \\
\text { Number }\end{array}$ & Total & Average & Variation \\
\hline Mo & 4 & 126.8 & 31.7 & 0.046667 \\
Mo+GA3 & 4 & 131.6 & 32.9 & 1.206667 \\
Mo+EDDS & 4 & 124.8 & 31.2 & 2.926667 \\
Mo+GA3+EDDS & 4 & 130.9 & 32.725 & 4.009167 \\
Control & 4 & 126.1 & 31.525 & 1.215833 \\
\hline
\end{tabular}

\begin{tabular}{lllllll}
\hline ANOVA & & & & & \\
\hline Source of Variation & SS & df & MS & F & P value & Threshold Value \\
\hline between groups & 9.163 & 4 & 2.29075 & 1.217836 & 0.344414 & 3.055568 \\
within groups & 28.215 & 15 & 1.881 & & & \\
& & & & & & \\
Total & 37.378 & 19 & & & & \\
\hline
\end{tabular}

Table 2. Results of the ANOVA test

\subsection{Discussion on the Difference of Heavy Metal Uptake and Accumulation in Sunflower Plants in Different Operations Conditions}

After comparing the height growth of the plants, the difference of accumulated concentration of heavy metals in the roots and above parts (shoots, leaves, petals and seeds) of the sunflowers after the addition of chelate and phytohormones was examined.

According to the results shown in Table 13, the Mo concentration in the root parts in all the groups was smaller than the ICP detection limit, and could not be detected. After calculating the analyzed samples collected from different 
plant parts, the researcher found that the minimum detectable concentration of ICP was $0.001 \mathrm{mg} / \mathrm{L}$; therefore, the results indicated that the Mo concentration in the root parts was specifically low.

As the results exhibit in Figures 5-8 and Tables 14-17, the Mo concentration in the plants was low, and the Mo concentration in the plants' shoots, leaves and petals in certain of the groups failed to be detected. Because Mo is one of the essential elements required for plant growth and metabolism (Rascioa et al., 2011), a small amount of Mo content has no impact on plants. In addition, according to previous relevant documents, when a plant lacks nutrient elements with medium mobility (such as N, P, S and Mo), some symptoms may appear on the leaves. For instance, Mo deficiency is similar to $\mathrm{N}$ deficiency, which makes the leaves have yellow striping; and the leaf edges will curl and become scorched (Chang et al., 2003). Consequently, it is estimated that certain Mo content might be absorbed by the plants for the demands of growth and metabolism when Mo was transported in the plants. Mo concentration was detected in the seeds of all the groups, meaning that rest of the Mo content had moved to the seeds after the plants' uptake; thus, it is concluded that Mo has higher upward transport ability inside plants. Furthermore, after observing the accumulated Mo concentration in the respective parts, the researcher found that the groups with the addition of chelate had higher Mo concentration compared to the other groups, after the plants' uptake, indicating that the addition of chelate can enhance the transport of heavy metals in soil, and increase both heavy metals' mobility and transport from plant roots to the above parts of plants through the dissolution and complexation of heavy metals. The bound heavy metals can accumulate in the roots and be effectively transported to the above parts (Nowack et al., 2006).

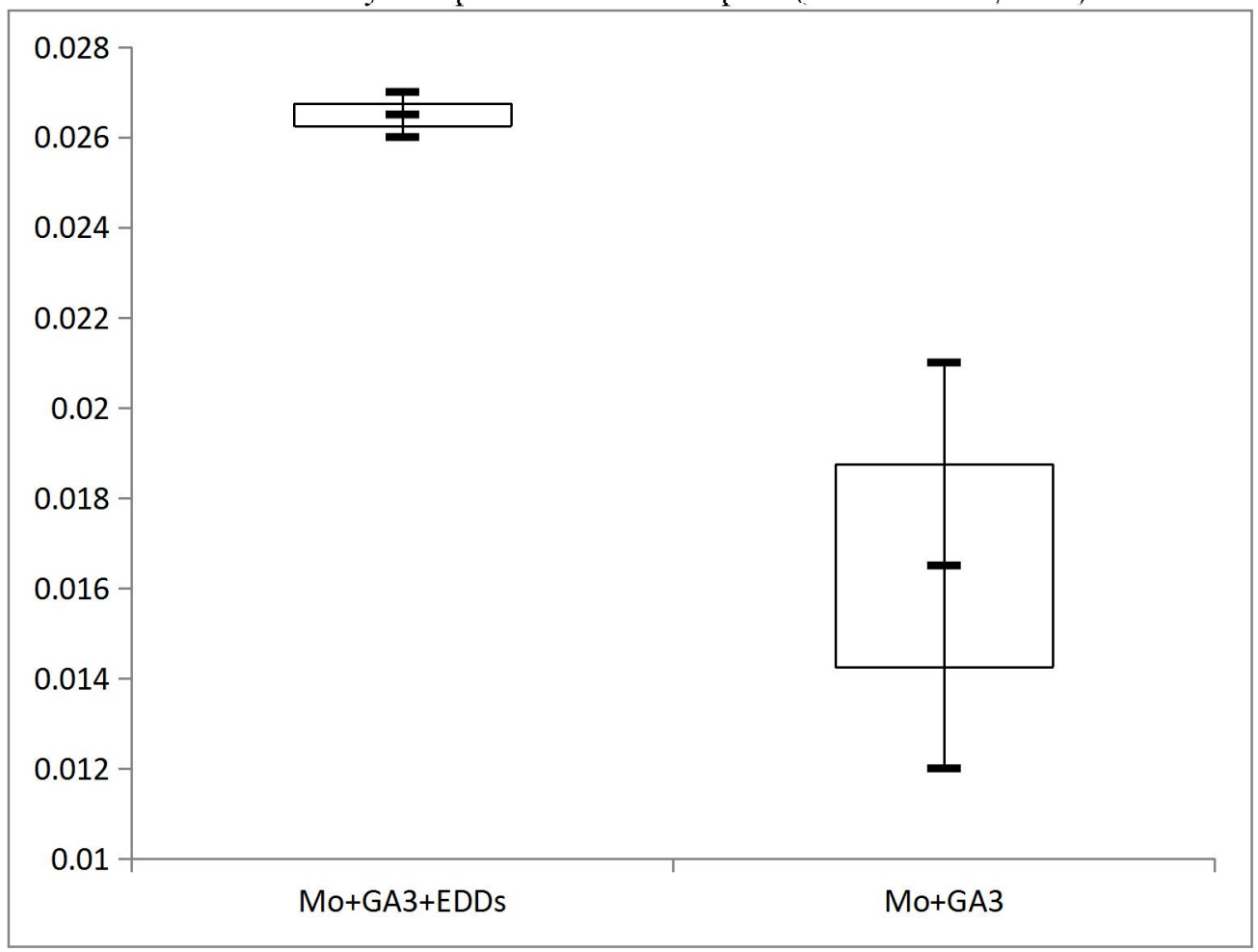

Figure 5; Concentration of heavy metal accumulation in the shoots of the respective groups. 


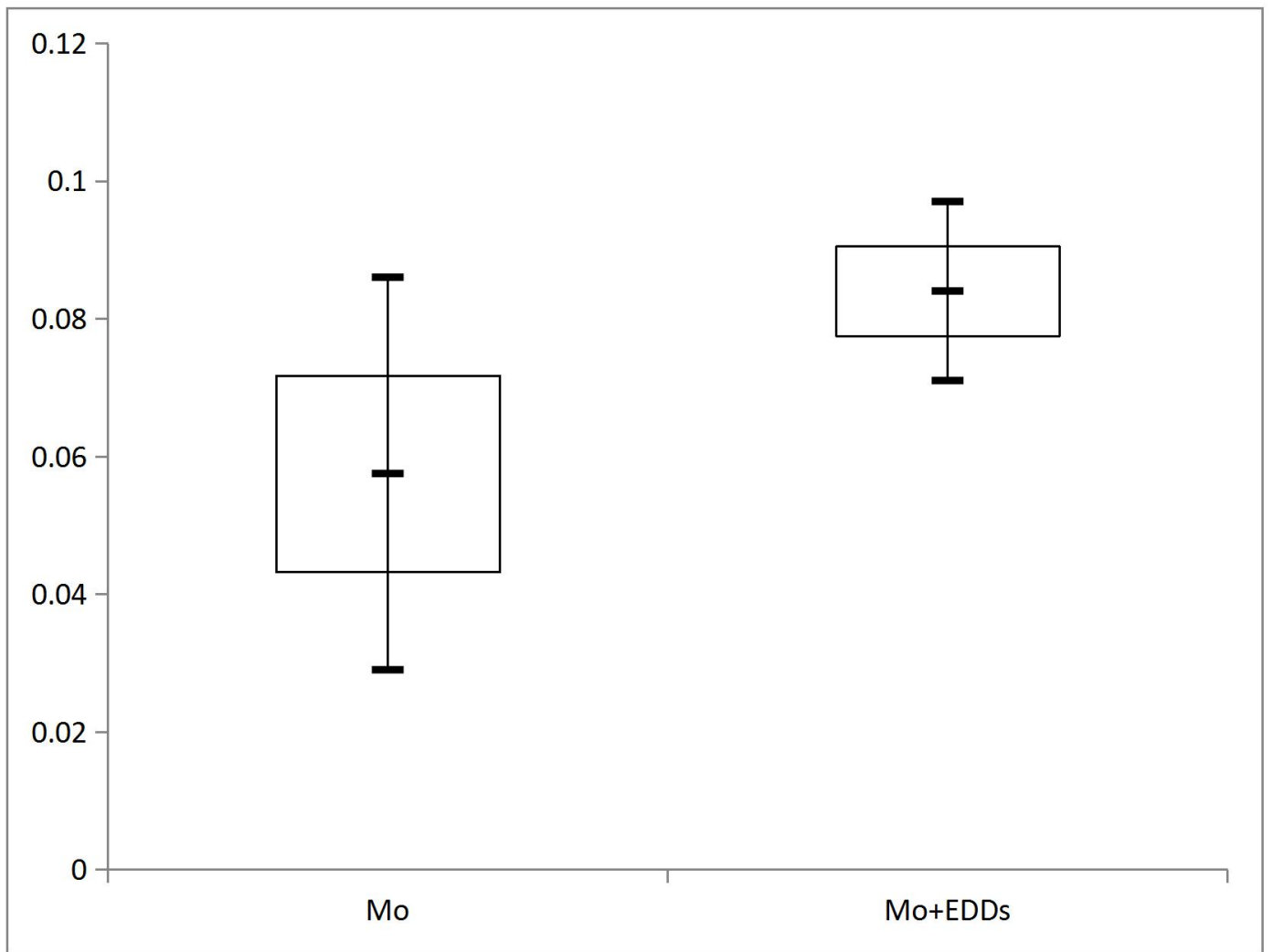

Figure 6; Concentration of heavy metal accumulation in the leaves of the respective groups.

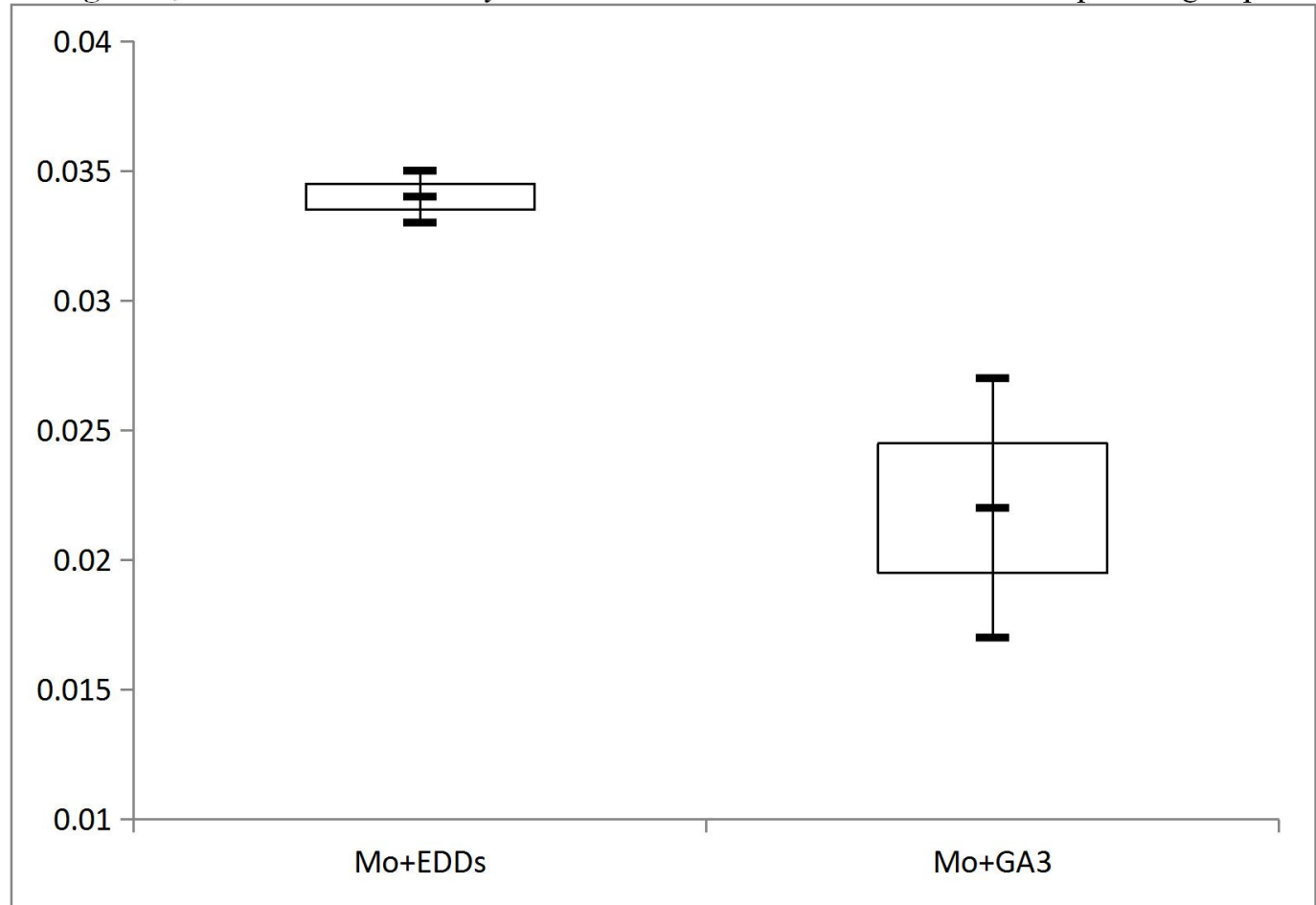

Figure 7; Concentration of heavy metal accumulation in the petals of the respective groups.

Through the pot experiment, it is concluded that adding chelate is specifically helpful in the transport of heavy metals in soil. It can also assist plants in transporting heavy metals to the above parts, and increasing the heavy metal uptake. However, whether adding chelate can have any impact on plants, or exert any hazardous influence on the environment derived from the residual content in soil should be evaluated. The poisonous impact of chelate on plants can be improved by adding phytohormones. In addition, the half-life of EDDS in soil is 2.5 days, meaning that the content of EDDS in soil will be reduced rapidly as time passes, thereby lowering the risk of secondary contamination of 
the soil and underground water. Due to the fact that the Mo concentration in this study is too low to be detected, the concentrations of the roots and other parts remain unknown; thus the BCF, TF and PEF cannot be calculated, with the loss of the critical indications for quantifying the assessment of phytoremediation.

\section{Conclusion}

The project explores phytohormones and heavy metals on the growth scenario explants (explants morphological analysis) through the experiment. The results indicate that GA3 can increase the growth rate of the plants. The average incremental growth of the heavy-metal-added-only group is $21.0 \mathrm{~cm}$; of the GA3-added group it is $21.9 \mathrm{~cm}$; of the EDDS-added group, it is $20.3 \mathrm{~cm}$; of the GA3+ EDDS-added group, it is $21.7 \mathrm{~cm}$. We find out Mo is a fertilizer.

\section{Acknowledgement}

We thank ministry of science and technology, also Taiwan EPA

\section{References}

1. Abou-Shanab R.A.I, Delorme, T.A., Angle, J.S., Chaney, R.L., Ghanem, K., Moawad, H., Ghozlan, H.A.(2003) Phenotypic characterization of microbes in the rhizos-phere of Alyssum murale. International Journal of Phytoremediation 5(4), 367-379.

2. Ali, H., Khan, E. and Sajad, M.A. (2013) Phytoremediation of heavy metals - Concepts and applications. Chemosphere 91, 869-881.

3. Alloway, B.J., 1990. Heavy Metals in Soils. Blackie and Son, London, UK, p. 339.

4. Atlas, S.M. (1981) Microbial degradation of petroleum hydrocarbons: an environment perspective. Microbiological Review 45(1), 180-209.

5. Baker, A.J.M., Brooks, R.R. (1989) Terrestrial higher plants which hyperaccumulate metallic elements-review of their distribution, ecology and phytochemistry. Biorecovery 1(2), 81-126.

6. Bastianoni, S., Coppola, F., Tiezzi, E., Colacevich, A., Borghini, F., Focardi, S. (2008) Biofuel potential production from the Orbetello lagoon macroalgae: A comparison with sunflower feedstock. Biomass andBioenergy 32(7), 619-628.

7. Belimov, A.A., Hontzeas, N., Safronva, V.I., Demchinskaya, S.V., Piluzza, G., Bullitta, S., Glick, B.R. (2005) Cadmium-tolerant plant growth-promoting bacteria associated with the roots of Indian mustard (Brassica juncea L. Czern). Soil Biology and Biochemistry 37(2), 241-250.

8. Brown, S.L., Chaney, R.L., Angle, J.S., Baker, A.J.M. (1994) Phytoremediation potential of Thlaspicaerulescens and bladder campion for zinc- and cadmium-contaminated soil. Journal of Environment Quality 23(6), 11511157.

9. Crittenden, J.C., Berrigan, J.K., Hand, D.W., Lykins, B., 1987. Design of rapid fixed-bed adsorption tests for nonconstant diffusivities. Journal of Environmental Engineering 113(2), 243-259.

10. Davis, T.A., Volesky, B., Mucci, A. (2003) A review of the biochemistry of heavy metal biosorption by brown algae. Water Research 37(18), 4311-4330.

11. Delaune, R.D., Gamgrell, R.P., Pardue, J.H., Patrick, W.H.J. (1990) Fate of petroleum hydrocarbons and toxic organics in Louisiana coastal environment. Estuaries and Coasts 13(1), 72-80.

12. Evangelou, M.W.H., Bauer, U., Ebel, M., and Schaeffer, A. (2007) The influence of EDDS and EDTA on the uptake of heavy metals of $\mathrm{Cd}$ and $\mathrm{Cu}$ from soil with tobacco Nicotianatabacum. Chemosphere 68(2), 345-353.

13. Evangelou, M.W.H., Ebel, M. and Schaeffer, A. (2007) Chelate assisted phytoextraction of heavy metals from soil. Effect, mechanism, toxicity, and fate of chelating agents. Chemosphere 68, 989-1003.

14. Fässler, E., Evangelou, M.W., Robinson, B.H., Schulin, R. (2010) Effect of in-dole-3-acetic acid (IAA) on sunflower growth and heavy metal uptake in combination with ethylene diaminedisuccinic acid (EDDS).Chemosphere 80(8), 901-907.

15. Glick, B., karaturovíc, D., Newell, P. (1995) A novel procedure for rapid isolation of plant growth promoting Pseudomonas. Canadian Journal of Microbiology 41, 533-536.

16. Glick, B., Patten, C., Jolguin, G., Penrose, D. (1999) Biochemical and genetic mechanisms used by plant growth promoting bacteria. Imperial College Press, London, England.

17. Hadi, F., Bano, A., Fuller, M.P. (2010) The improved phytoremediation of lead $(\mathrm{Pb})$ and the growth of maize (Zea mays L.): the role of plant growth regulators (GA3 and IAA) and EDTA alone and in combinations. Chemosphere 80(4), 457-462.

18. Kabata-Pendias, A., 2001. Trace Elements in Soil and Plants. Boca Raton (FL), CRC Press, p. 128.

19. Kabata-Pendias, A., Pendias, H., 1984. Trace Elements in Soil and Plants. Boca Raton (FL), CRC Press, p. 315. Keller, M., Koblet, W., 1995. Stress-induced development 
20. Liphadzi, M.S., Kirkham, M.B. (2006) Availability and plant uptake of heavy metals in EDTA-assisted phytoremediation of soil and composted biasolids. South African Journal of Botany 72(3) 391-397.

21. Liu, D., Li, T., Islam, E., Jin, X., Mahmood, Q. (2007) Enhanced of lead uptake by hyperaccumulator plant species Sedum alfrediiHance using EDTA and IAA. Bulletin of Environmental Contamination andToxicity 78(3-4), 280-283.

22. López, M.L., Peralta-Videa, J.R., Benitez, T., Gardea-Torresdey, J.L. (2005) Enhancement of lead uptake by alfalfa (Medicago sativa) using EDTA and a plant growth promoter. Chemosphere 64(4), 595-598.

23. Lucy, M., Reed, E., Glick, B.R. (2004) Applications of free living plant growth-promoting rhizobacteria.Antonie Van Leeuwenhoek 86(1), 1-25.

24. Luo, C.L., Shen, Z.G., Li, X.D. (2005) Enhanced phytoextraction of Cu, Pb, Zn and Cd with EDTA and EDDS. Chemosphere 59(1), 1-11.

25. Ma, Y., Rajkumar, M., Freitas, H. (2009) Inoculation of plant growth promoting bacterium Achromobacterxylosoxidans strain Ax10 for the improvement of copper phytoextraction by Brassicajuncea. Journal of Environment Management 90(2), 831-837.

26. Meers, E., Vandecasteele, B., Ruttens, A. (2007) Potential of five willow species (Salix spp.) for phytoextraction of heavy metals. Environmental and Experimental Botany 60(1), 57-68.

27. Nowack, B., Schulin, R., Robinson, B.H. (2006) Critical assessment of chelant-enhanced metal phytoextraction, Environ. Sci. Technol., 40,.5,225-5,232.

28. Rai, P.K., Mallick, N., Rai, L.C., 1993. Physiological and biochemical studies on an acid-tolerant Chlorella vulgaris under copper stress. Journal of General and Applied Microbiology 39, 529-540.

29. Rascioa,N., Navari-Izzo,F.(2011) Heavy metal hyperaccumulating plants: How and why do they do it? And what makes them so interesting. Plant Science. 180, 169-181.

30. Rocha, C.G., Zaia, D.A.M., da Silva Alfaya, R.V., da Silva Alfaa, A.A. (2009) Use of rice straw as biosorbent for removal of $\mathrm{Cu}(\mathrm{II}), \mathrm{Zn}(\mathrm{II}), \mathrm{Cd}(\mathrm{II})$ and $\mathrm{Hg}(\mathrm{II})$ ions in industrial effluents. Journal of Hazardous Materials 166(1), 383-388.

31. Salt, D.E., Smith, R.D., Raskin, I. (1998) Phytoremediation. Annual Review of Plant Physiology andPlant Molecular Biology 49, 643-668.

32. Siedlecka, A., 1995. Some aspects of interactions between heavy metals and plant mineral nutrients. Acta Societatis Botanicorum Poloniae 64, 265-272.

33. Skouloua, V., Mariolisb, N., Zanakis, G. and Zabaniotou, A. (2011) Sustainable management of energy crops for integrated biofuels and green energy production in Greece. Renewable Sustainable Energy Rev. 15, $1928-1936$.

34. Tassi, E., Pouget, J., Petruzzelli, G., Barbafieri, M. (2008) The effects of exogenous plant growth regulators in the phytoextraction of heavy metals. Chemosphere 71(1), 66-73.

35. Tessier, A., Campbell, P.G.C., Bisson, M. (1979) Sequential extraction procedure for the speciation of particulate trace metals. Analytical Chemistry 51(7), 844-851. 